\title{
Perioperative Hemostatic Management of Cardiohepatic Transplant with Rotational Thromboelastometry (ROTEM)
}

Kataife Ezequiel; Adrover Alejo; Mileo Federico; Viso Hugo

Hospital Italiano de Buenos Aires, CABA, Argentina

Introduction: Why is this case important?

- A double challenge: the coagulopathy of the end stage liver disease (ESLD) and the alteration of the extracorporeal circulation (ECC).

- Algorithms for haemostatic management of multiorgan transplants have not been published.

\section{Case Report: The Hemostatic Approach}

- Patient: 60 year old male.

- Diagnosis: 1. Cardiac Insufficiency $\rightarrow$ Viral Myocarditis 2. Liver Cirrhosis $\rightarrow$ Unknown Etiology

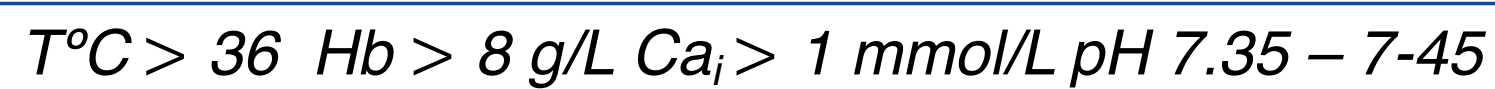

Cell Salvage +1 gr TXA then guided by ROTEM

Treat only if it bleeds in a stepwise approach

\begin{tabular}{|c|c|c|c|c|c|c|}
\hline THROMBOELASTOMETRY & TRANSPLANT & EXTEM & INTEM & FIBTEM & APTEM & HEPTEM \\
\hline PRE ECC & \multirow{3}{*}{ HEART } & $\mathrm{x}$ & $\mathrm{x}$ & $\mathrm{x}$ & & \\
\hline INTRA ECC & & $x$ & & $x$ & & \\
\hline POSTPROTAMINE & & $\mathrm{y}$ & $\mathrm{y}$ & $\mathrm{y}$ & & $\mathrm{y}$ \\
\hline BASAL HEPATIC & \multirow{3}{*}{ LIVER } & $\boldsymbol{A}$ & $\boldsymbol{\lambda}$ & $\boldsymbol{\lambda}$ & & $\boldsymbol{\lambda}$ \\
\hline ANHEPATIC & & $x$ & $\mathrm{x}$ & $\mathrm{x}$ & $\mathrm{x}$ & \\
\hline REPERFUSION & & $x$ & $x$ & $x$ & $x$ & $\mathrm{x}$ \\
\hline
\end{tabular}

STEP: Post-Protamine / Basal
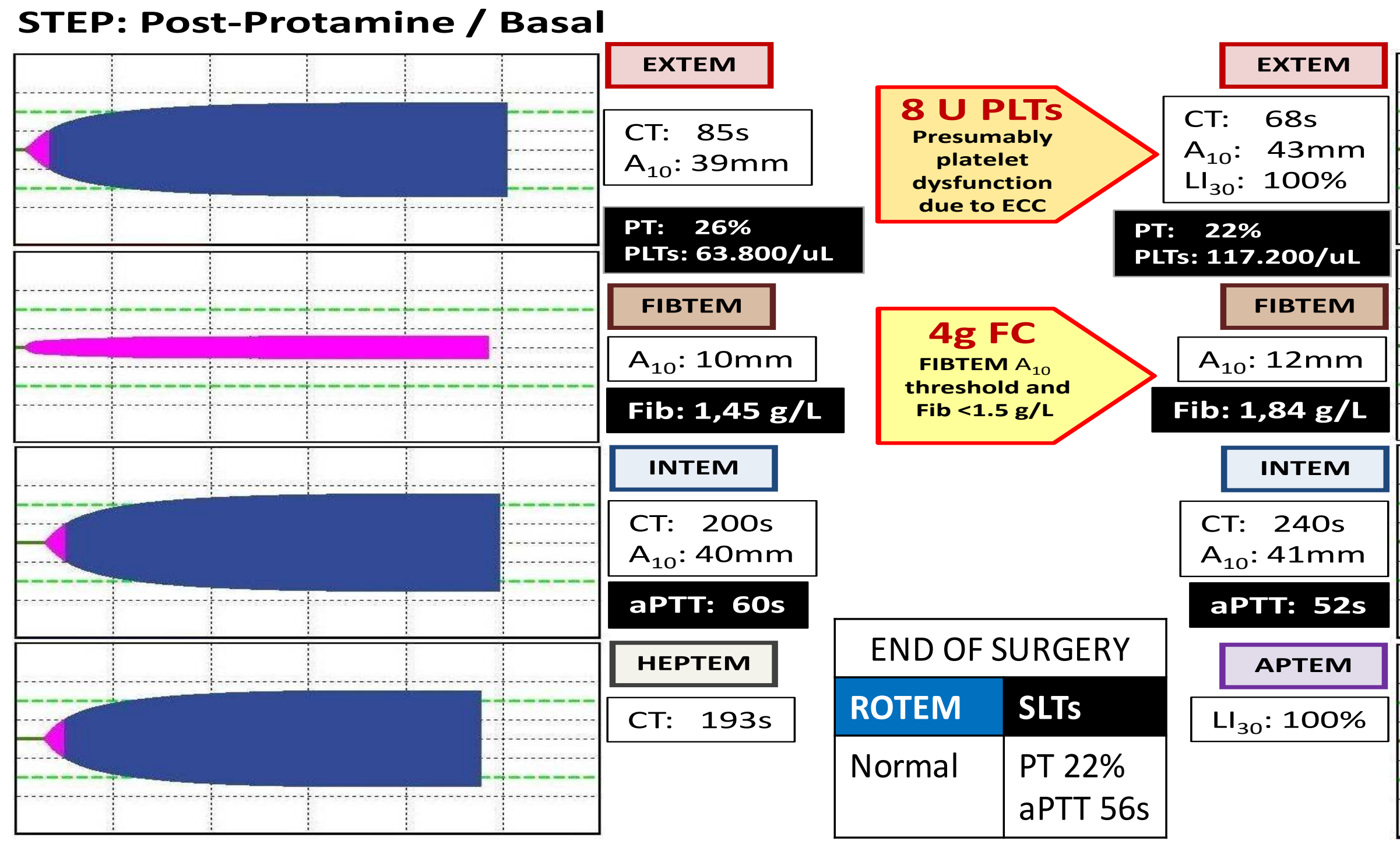

STEP: Anhepatic

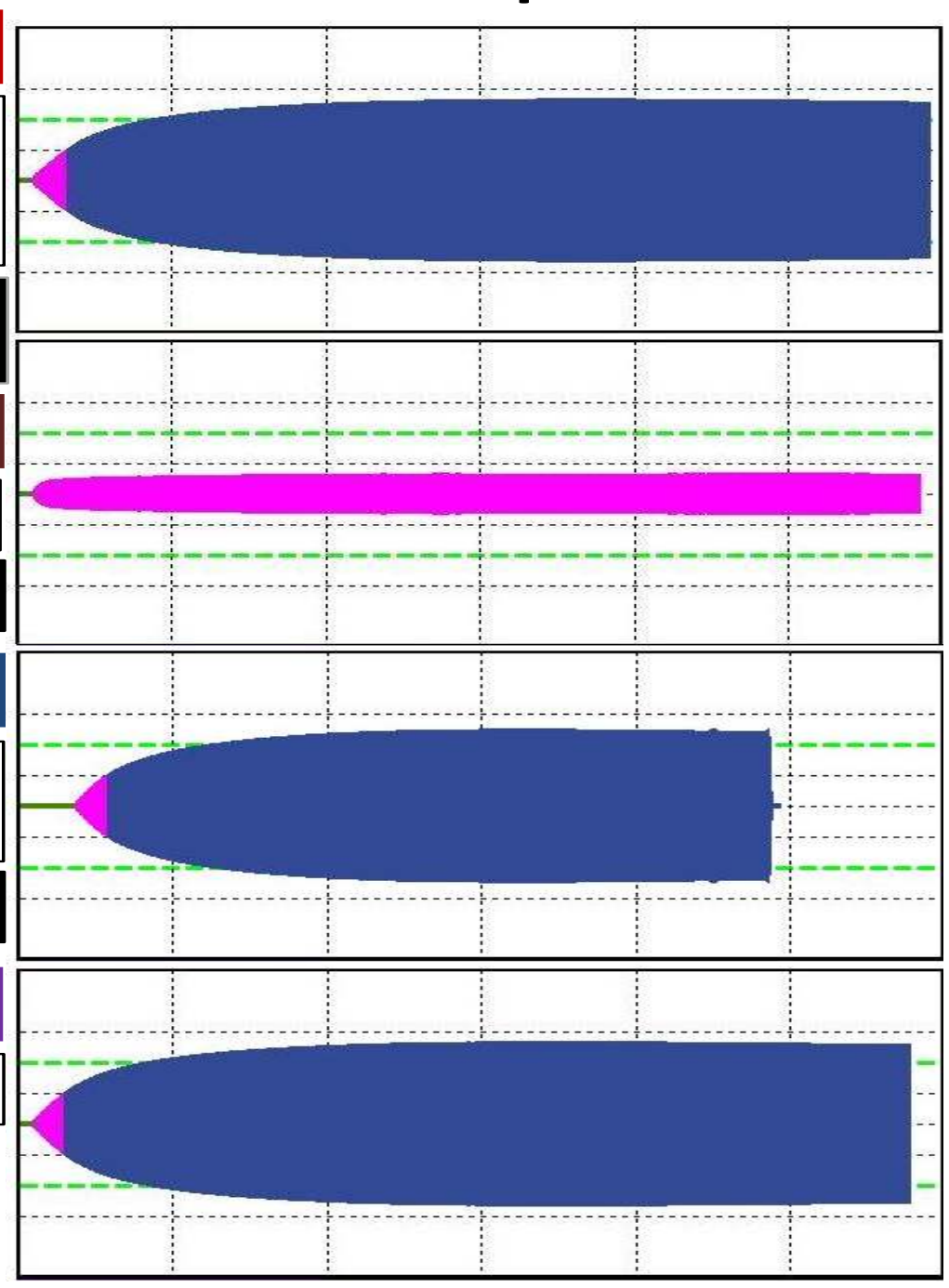

\section{Discussion}

- Standard laboratory tests (SLTS) were not designed to guide transfusion therapy in this kind of setting.

- SLTS do not show the whole thrombin formation, neither clot strength nor the presence of hyperibrinolysis. Therefore, they do not provide a physiologic view of the hemostatic system.

- Current studies indicate that hemostatic therapy guided by viscoelastic test reduces allogeneic transfusions and their adverse events.
(2) Pre-ECC
(a) Intra - ECC
EXTEM
$C T$
$40-80 s$
() Postprotamine
() Anhepatic
() Reperfusion
FIbTEM A10 $10-24 \mathrm{~mm}$

(2)

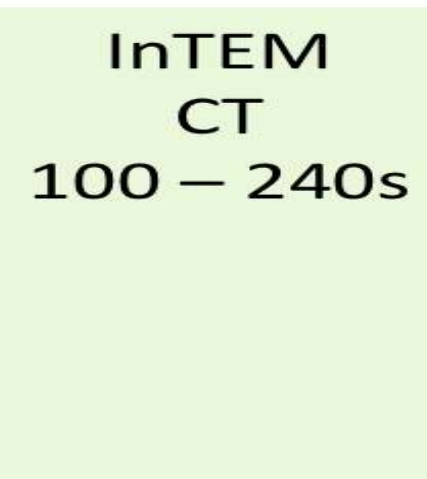

(a)

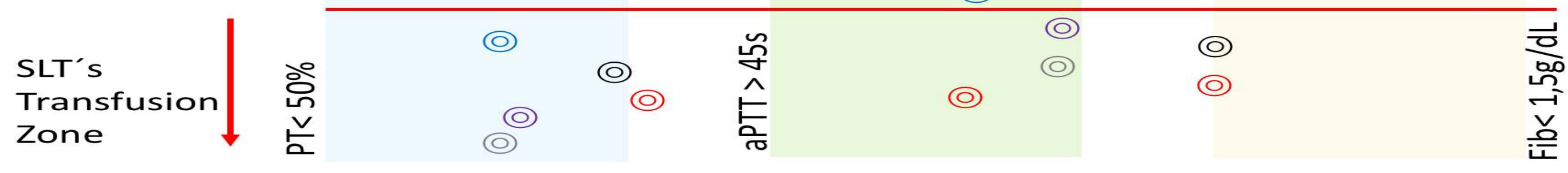

\section{Learning Points and Future Research Directions}

$\checkmark$ There is a poor correlation between SLTS and ROTEM. SLTS overestimate transfusion requirements.

$\checkmark$ ROTEM guided algorithm based on factor concentrates therapy allows the reduction of allogeneic transfusions in cardiohepatic transplant.

\section{$\checkmark$ Can we reduce mortality?}

1. K. Görlinger et al. Coagulation management in patients undergoing mechanical circulatory support. Best Pract Res Clin Anaesthesiol (2012) Jun; 26(2): 179-98 2. Kirchner, et al. Coagulation management with factor concentrates in liver transplantation: a single center experience. Transfusion (2014) Oct; 54 (10 Pt2): $2760-8$. 